\title{
Enhanced intercalation of organo-muscovite prepared via hydrothermal reaction at low temperature
}

\author{
LIM WENG-LIP', NORLIYANA MOHD SALLEH'2 NURUL 'AQILAH ABDUL RAHMAN', \\ NUR SURAYA ANIS AHMAD BAKHTIAR', HAZIZAN MD AKIL ${ }^{1}$ \\ and SYAZANA AHMAD ZUBIR ${ }^{1, *}$ (D) \\ ${ }^{1}$ School of Materials and Mineral Resources Engineering, Engineering Campus, Universiti Sains Malaysia, \\ 14300 Penang, Malaysia \\ ${ }^{2}$ Centre for Drug Research, Universiti Sains Malaysia, 11800 Penang, Malaysia \\ *Author for correspondence (syazanazubir@usm.my)
}

MS received 12 June 2018; accepted 14 May 2019

\begin{abstract}
Muscovite clay is an ideal reinforcing filler due to its high-aspect ratio. However, it does not swell in water, making it hard to be treated and intercalated. In this study, ion exchange treatment is carried out on muscovite clay using cetyltrimethylammonium bromide (CTAB) cations via two-step intercalation method. The intercalation steps included: inorganic-inorganic ion exchange treatment and inorganic-organic ion exchange treatment under hydrothermal conditions. The intercalation of muscovite particles was examined with various techniques to analyse the physical and chemical changes. Furthermore, the hydrothermal conditions for effective $\mathrm{CTA}^{+}$ion intercalation within muscovite interlayers prepared via the hydrothermal process at low temperature, $180^{\circ} \mathrm{C}$, under different hydrothermal reaction times and CTAB/Li-Mus mass ratio were investigated. Fourier transform infra-red (FTIR) analysis revealed that the $\mathrm{CTA}^{+}$ions are diffused into the interlayers of aluminosilicate and formed a strong electrostatic bond with the clay surface. X-ray powder diffraction analysis showed that the interplanar spacing in the organo-muscovite samples is almost identical as the hydrothermal reaction time is prolonged beyond $12 \mathrm{~h}$. An optimum limit of the CTAB to Li-Mus ratio is observed as the $d_{002}$ plane spacing is increased with an increase of the mass ratio of CTAB to Li-Mus up to $1.0 \mathrm{C}$ and decreased with a further increase in the mass ratio. In addition, the intercalated $\mathrm{CTA}^{+}$chains are homogenously distributed and formed a paraffin-like arrangement in the muscovite clay. Besides, the structure of aluminosilicate layers is not affected or damaged after both treatments according to FTIR analysis.
\end{abstract}

Keywords. Muscovite; intercalation; organic ion exchange treatment; layered silicates.

\section{Introduction}

Clay silicates have been widely employed in a variety key area of applications including absorbents, electrode modifiers, catalysts, as well as filler materials, sealants and suspending medium in many applications $[1,2]$. The type of layered silicates that are extensively studied and used as reinforcement phase in polymer composite are smectite, especially montmorillonite [3-5] and saponite [6,7]. The nature of swelling behaviour of both layered silicates has made them favourable in the organic cation exchange treatment $[8,9]$. In addition, there is another type of layered silicate mineral i.e., mica, especially muscovite that has gradually attracted the attention among researchers recently. Various studies on muscovite reinforced polymer composites had been performed [10-12]. Basically, muscovite is a potassium-rich mica [13] where each of its unit cells (composed of two silica tetrahedral sheets and an alumina octahedral sheet in the form of sandwich structure) are bonded by $\mathrm{K}^{+}$ions $[14,15]$. Moreover, muscovite has a higher aspect ratio than montmorillonite [10], making it more suitable as an ideal reinforcing material for polymer composites.

The properties of polymer composites are significantly influenced by the dispersion of layered silicate fillers in the polymer matrix. Generally, dispersion of neat-layered silicates in the polymer matrix is limited due to the natural surface hydrophilicity of aluminosilicate layers [16]. Hence, minimized the compatibility of layered silicates in the polymer matrix [17]. However, the incompatibility issue of silicate particles can be overcome by altering their surface nature from hydrophilic to hydrophobic via ion exchange treatment [11].

It is noted that ion exchange and intercalation of muscovite are not easily performed as it does not swell in water. Basically, strong electrostatic bonding is formed between the interlayer cation chains and aluminosilicate layers of muscovite due to homogeneous charge distribution on aluminosilicate layers [18]. Thus, it is difficult to intercalate the muscovite particles with organic cations 
using a conventional direct ion exchange treatment method [8]. To address this issue, specific modification on the interlayer cations of muscovite particles was carried out; for instance, ion exchange treatment with other inorganic ions.

Previously, different groups of researchers [19-21] had utilized $\mathrm{Li}$ and other alkaline earth metals ( $\mathrm{Ba}, \mathrm{Ca}$ and $\mathrm{Mg}$ ) as the inorganic cations as first-step ion exchange treatment to modify the muscovite structure. However, the muscovite structure obtained after delamination was not satisfactory. In 2005, a breakthrough was obtained by Zhao and coworkers [22], where delaminated muscovite particles with a high-specific surface area were successfully prepared using hot saturated $\mathrm{LiNO}_{3}$ solution to treat the muscovite powder. After $\mathrm{LiNO}_{3}$ treatment, the muscovite particles were more favourable for the organic intercalation process as their basal spacing was expanded significantly.

The aim of organic ion exchange treatment is to alter their surface property into hydrophobic. Basically, quaternary ammonium ions are the common organic cations used in organic ion exchange treatment [23]. One of the organic cations that are frequently used to modify the muscovite surface property is cetyltrimethylammonium ions $\left(\mathrm{CTA}^{+}\right)$. Muscovite particles were intercalated by $\mathrm{Yu}$ and coworkers [9] using cetyltrimethylammonium bromide (CTAB) as an organic surfactant via a hydrothermal reaction at $200^{\circ} \mathrm{C}$ which resulted in an increment of muscovite interlayers spacing up to $27.4 \AA$. In a recent paper, Che Ismail et al [24] reported the structural changes of intercalated organomuscovite clay prepared using different concentrations of the surfactant.

Although various studies have been carried out on the preparation of organo-muscovite with different amines, yet there is a lack of information available on the effect of the hydrothermal reaction time and the CTAB to Li-muscovite concentration ratio prepared at low temperature, $180^{\circ} \mathrm{C}$. Hence, this study was conducted with the aim of altering the hydrophilic nature of muscovite particles into organomuscovite via the two-step intercalation method using $\mathrm{LiNO}_{3}$ treatment and $\mathrm{CTAB}$ as the organic surfactant at $180^{\circ} \mathrm{C}$ hydrothermal reaction. $\mathrm{LiNO}_{3}$ treatment was chosen since the solution does not alter the structural and chemical compositions of muscovite [8,24], whereas alkylammonium cations are well known to be easily adsorbed on muscovite crystals forming stable molecules with different arrangements [9]. The chemical, morphological and structural changes of the intercalated muscovite clay were investigated. In addition, the hydrothermal conditions for the effectiveness of $\mathrm{CTA}^{+}$ions intercalated within muscovite interlayers at different hydrothermal reaction times and CTAB/Li-Mus mass ratios were studied and the structural changes and orientation of CTAB molecules were analysed. Based on the analyses result, the optimum intercalation of muscovite particles using an organic surfactant, i.e., CTAB could be accomplished at a certain hydrothermal reaction time and CTAB concentration.

\section{Experimental}

\subsection{Materials}

Muscovite powder, $2 \mathrm{M}_{1}$ was obtained from Lingshou County Xinfa Mineral Co. Ltd., China. Lithium nitrate powder $\left(\mathrm{LiNO}_{3}\right.$, purity $\geq 99 \%$ ) was purchased from Alfa Aesar, USA and CTAB (purity $\geq 98 \%$ ) was obtained from Merck.

\subsection{Synthesis of Li-Mus and CTA-Mus powders}

Li-muscovite (Li-Mus) and CTA-muscovite (CTA-Mus) were prepared based on the modified method by Yu and coworkers [9]. Muscovite powder, $2 \mathrm{M}_{1}$ was mechanically mixed with $\mathrm{LiNO}_{3}$ powder in a ratio of 1:17 (muscovite: $\mathrm{LiNO}_{3}$ ) using ball mill for $2 \mathrm{~h}$. Subsequently, the mixture was heated in a furnace at $300^{\circ} \mathrm{C}$ for $12 \mathrm{~h}$. The product was then filtered and washed repeatedly three times using deionized water, followed by drying in an oven at $100^{\circ} \mathrm{C}$ for $24 \mathrm{~h} . \mathrm{LiNO}_{3}$ treatment was repeated for three times and the final product was named Li-Mus. Then, organo-muscovite $\left(\mathrm{CTA}^{+}\right.$-muscovite, CTA-Mus) powder was prepared using CTAB as the cationic surfactant under hydrothermal conditions. In this study, two parameters were varied during the hydrothermal reaction, which were (1) reaction time and (2) mass ratio of CTAB to Li-Mus.

For the study of the hydrothermal reaction time, CTA-Mus particles were prepared using 0.5 mass ratio of CTAB to LiMus. First, $1.6 \mathrm{~g}$ of CTAB powder was dissolved in $400 \mathrm{ml}$ deionized water. Then, $3.2 \mathrm{~g}$ of Li-Mus was added and mixed with aqueous CTAB solution at room temperature. Subsequently, the mixtures were placed in a hydrothermal reactor equipped with a Teflon-lined stainless-steel autoclave and reacted under hydrothermal conditions at $180^{\circ} \mathrm{C}$ for 12,16 , 20 and $24 \mathrm{~h}$, respectively. The surfactant-muscovite product (CTA-Mus) was then filtered and washed with ethanol three times. The filtered paste was dried in an oven at $50^{\circ} \mathrm{C}$ for $12 \mathrm{~h}$ and ground using an agate mortar. The prepared samples were named CTA-Mus 12, CTA-Mus 16, CTA-Mus 20 and CTA-Mus 24.

The investigation on the CTAB to Li-Mus mass ratio was performed after the optimum hydrothermal reaction time was selected. In this study, the CTA-Mus particles with different CTAB to Li-Mus mass ratios $(0.5 \mathrm{C}, 1.0 \mathrm{C}$ and $1.5 \mathrm{C})$ were prepared under hydrothermal conditions at $180^{\circ} \mathrm{C}$ for $12 \mathrm{~h}$. The samples prepared were labelled as CTA-Mus 0.5C, CTAMus 1.0C and CTA-Mus 1.5C.

\subsection{Characterization of Li-Mus and CTA-Mus powders}

The X-ray fluorescence (XRF) spectrometer (Rigaku Rix 3000) was used to identify the elements present in the raw and treated muscovite particles by pressing $1 \mathrm{~g}$ of muscovite particles into a $13 \mathrm{~mm}$ diameter cylindrical pellet with $2 \mathrm{~mm}$ thickness as the XRF sample. The amount of each element 
present in the treated and untreated muscovite samples was obtained using XRF analysis.

$\mathrm{X}$-ray powder diffraction (XRD) analysis was performed using a PANalytical X-ray diffractometer (X'Pert PRO MRD PW 3040/60 generator, PANalytical). The X-ray beam employed was derived from $\mathrm{CuK} \alpha$ radiation (wavelength, $\lambda=0.154 \mathrm{~nm}$ ) in a sealed tube operated at $40 \mathrm{kV} / 35 \mathrm{~mA}$. Measurements were collected at the $2 \theta$ angle range for both the wide angle (from 1 to $50^{\circ}$ ) and small angle (from 1 to $\left.10^{\circ}\right)$. Furthermore, the scan step time and step size parameter used in the XRD analysis were $2.5 \mathrm{~s}$ and $0.05^{\circ}$, respectively.

The elemental bonding present in the treated and untreated muscovite particles was examined using an Fourier transform infrared (FTIR) spectrometer (Spectrum One FTIR spectrometer, PerkinElmer). Each specimen was scanned with 32 scans over the mid-infrared frequency wavelength in the range of $550-4000 \mathrm{~cm}^{-1}$. A KBr pellet measurement method with a resolution of $4 \mathrm{~cm}^{-1}$ was performed on each sample during FTIR measurement.

Morphological analysis of samples was acquired using scanning electron microscopy (SEM) (Zeiss Supra 35VP, Germany) operated at $5 \mathrm{kV}$. In addition, energy dispersive X-ray (EDX) spectroscopy analysis was also performed on the samples to identify the elements of the samples.

Samples for transmission electron microscopy (TEM) analysis were prepared by dispersing the powder in ethanol using ultrasonic for $30 \mathrm{~min}$. Next, drops of the dispersed sample were placed onto a copper grid and dried in air. High-resolution TEM (HRTEM) analysis was carried out on treated and untreated muscovite using TECNAI G ${ }^{2} 20$ S-Twin, FEI HRTEM operated at $200 \mathrm{kV}$.

\section{Results and discussion}

\subsection{Intercalation of $\mathrm{Li}^{+}$ions into muscovite}

Muscovite is composed of negatively-charged aluminosilicate layers and $\mathrm{K}^{+}$cation layers in alternate positions, parallel to the (001) plane [25]. Basically, muscovite particles do not swell like other layered silicates during interactions with water due to the existence of strong electrostatic bonding between aluminosilicate layers with $\mathrm{K}^{+}$cations [18]. Therefore, the cleaving process is necessary to ensure the muscovite particles are intercalated with an organic surfactant. Muscovite particles are cleaved by using the molten alkaline cations, $\mathrm{Li}^{+}$at $300^{\circ} \mathrm{C}$ [22] to allow the organic ion exchange treatment to be held easily. Figure 1 shows the intercalation procedure of muscovite particles. Raw muscovite was first treated with $\mathrm{LiNO}_{3}$ solution to swell the interlayer spacing of the particles. The small Li cations entered the vacant sites of the octahedral layer of muscovite during $\mathrm{LiNO}_{3}$ treatment and caused a partial release of $\mathrm{K}^{+}$ions between the clay layers. As a result, strong electrostatic force between layers was reduced and resulted in the interlamellar expansion [25].

Figure 2 shows the X-ray diffractograms of raw muscovite, Li-Mus after first-time and third-time $\mathrm{LiNO}_{3}$ treatments.

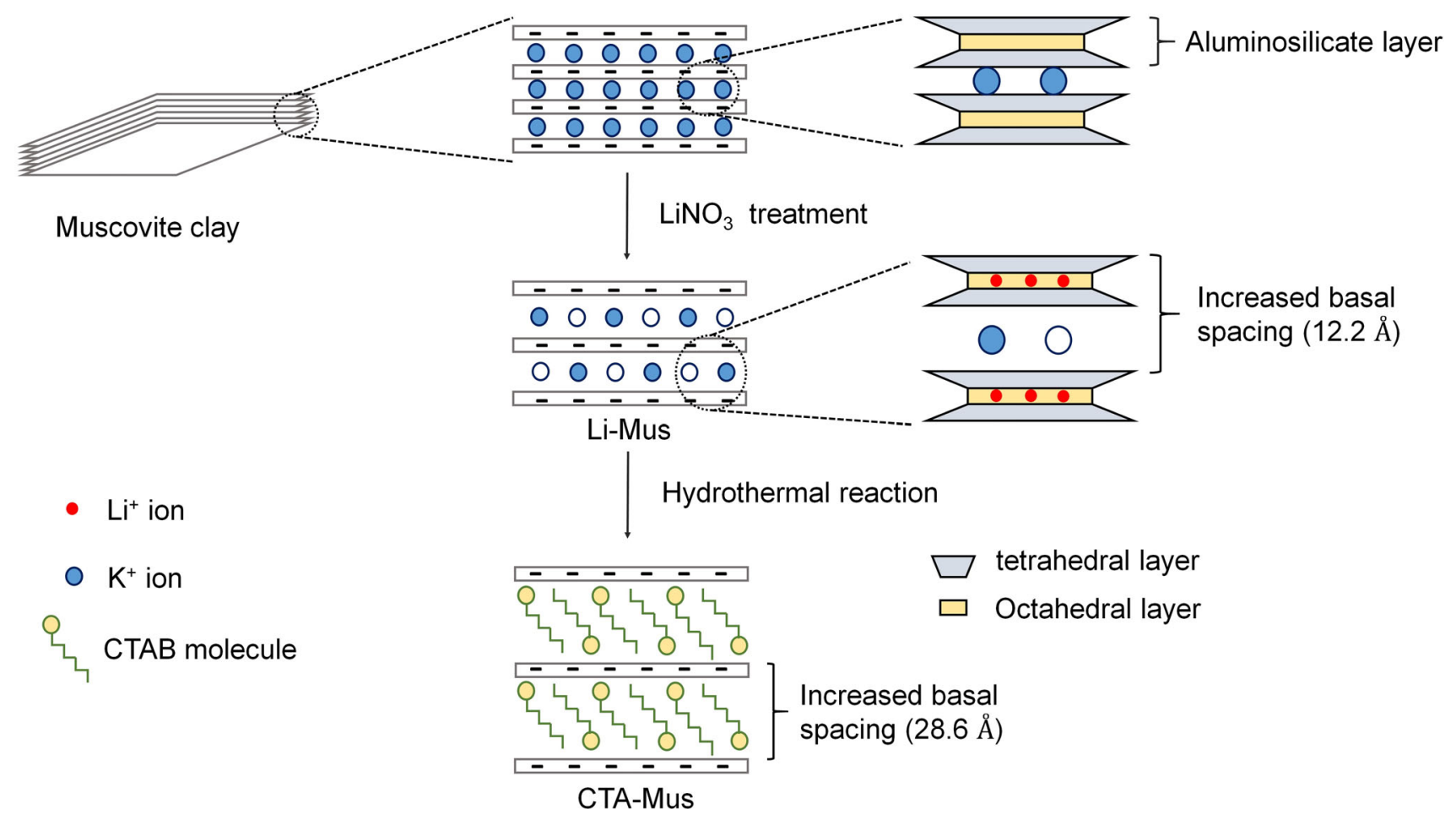

Figure 1. Intercalation procedure of muscovite particles. 


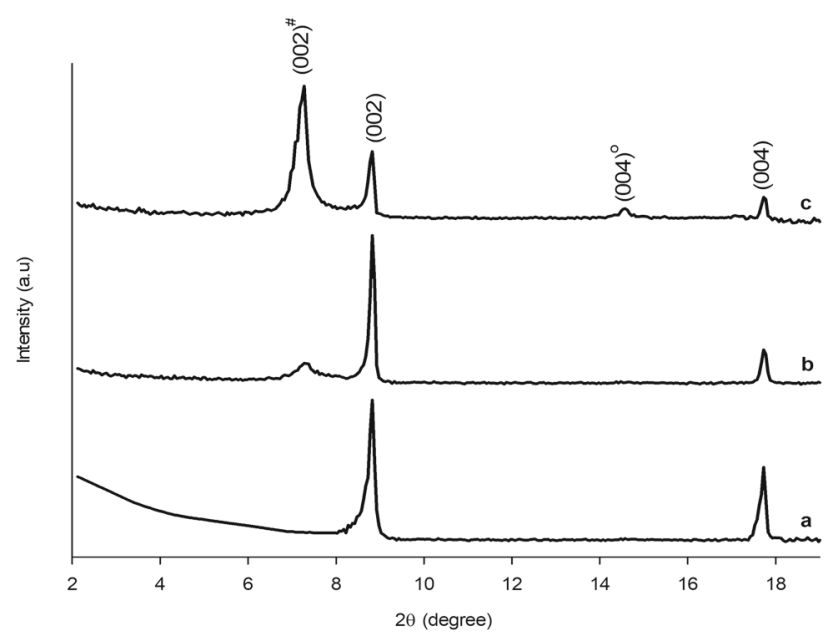

Figure 2. XRD patterns of samples: (a) muscovite $2 \mathrm{M}_{1}$, (b) LiMus after first $\mathrm{LiNO}_{3}$ treatment and (c) Li-Mus after third $\mathrm{LiNO}_{3}$ treatment.

Table 1. $d$-values of diffraction (001) for muscovite $2 \mathrm{M}_{1}, \mathrm{Li}$ Mus after first $\mathrm{LiNO}_{3}$ treatment and Li-Mus after third $\mathrm{LiNO}_{3}$ treatment.

\begin{tabular}{|c|c|c|}
\hline \multirow[b]{2}{*}{ Samples } & \multicolumn{2}{|c|}{$d$-values of diffraction $(001), \AA$} \\
\hline & $d_{002} \#$ & $d_{004^{\circ}}$ \\
\hline Muscovite $2 \mathrm{M}_{1}$ & 10 & 5 \\
\hline $\begin{array}{l}\text { Li-Mus after first } \\
\mathrm{LiNO}_{3} \text { treatment }\end{array}$ & 12.1 & - \\
\hline $\begin{array}{l}\mathrm{Li}-\mathrm{Mus} \text { after third } \\
\mathrm{LiNO}_{3} \text { treatment }\end{array}$ & 12.2 & 6.1 \\
\hline
\end{tabular}

The changes occur in the $d$-spacing of aluminosilicate interlayers in the muscovite after ion exchange treatments were calculated by using the Bragg's law and are summarized in table 1.

After the first-time $\mathrm{LiNO}_{3}$ treatment, some changes occurred on the muscovite structure as the new diffraction peak for $\left(d_{002}\right)$ was visible around $2 \theta=7.2^{\circ}$ (figure $2 \mathrm{~b}$ ). The relative intensity of a new diffraction peak increased with the number of $\mathrm{LiNO}_{3}$ treatments. Thus, the diffraction peaks of new $\left(d_{002}\right)$ and $\left(d_{004}\right)$ of muscovite were visibly emerged after third-time $\mathrm{LiNO}_{3}$ treatment (figure 2c). In addition, the diffraction peak for the $(004)$ plane (around $2 \theta=14.4^{\circ}$ ) became more visible after the third treatment compared to the first $\mathrm{LiNO}_{3}$ treatment. Furthermore, the intensity of original muscovite peaks was reduced after third $\mathrm{LiNO}_{3}$ treatment. Based on the results obtained, it can be concluded that three times of $\mathrm{LiNO}_{3}$ treatment is sufficient to enlarge the basal spacing of muscovite aluminosilicate interlayers (12.2 ̊). A wider spacing of muscovite aluminosilicate interlayers is preferred for the $\mathrm{CTA}^{+}$cation exchange treatment.

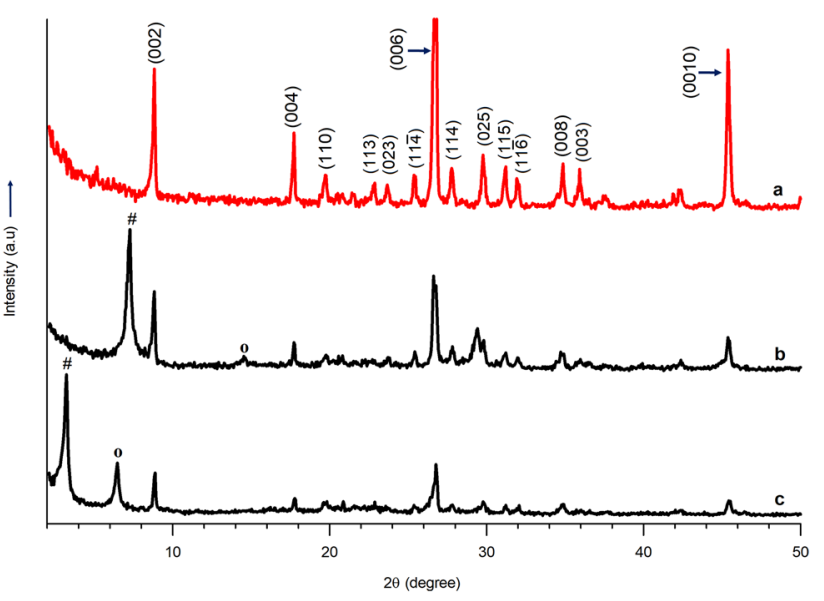

Figure 3. XRD patterns of (a) muscovite $2 \mathrm{M}_{1}$, (b) Li-Mus and (c) CTA-Mus.

Table 2. $d$-values of diffraction (001) of muscovite $2 \mathrm{M}_{1}$, Li-Mus and CTA-Mus.

\begin{tabular}{lcc}
\hline & \multicolumn{2}{c}{$d$-values of diffraction $(001), \AA$} \\
\cline { 2 - 3 } Samples & $d_{002^{\#}}$ & $d_{004}{ }^{\circ}$ \\
\hline Muscovite $2 \mathrm{M}_{1}$ & 10 & 5 \\
Li-Mus & 12.2 & 6.1 \\
CTA-Mus & 28.4 & 13.8 \\
\hline
\end{tabular}

\subsection{Characterization of CTA-Mus powder}

CTAB, acted as an organic surfactant, is an amphiphilic compound which contains hydrophilic (head) and hydrophobic (tail) parts. During the hydrothermal reaction of Li-Mus with CTAB, the CTAB molecules were intercalated within the aluminosilicate clay layers, hence, increased the basal spacing. During the intercalation process, the positive polar heads of $\mathrm{CTA}^{+}$cations were attached on the hydrophilic surfaces of aluminosilicate clay layers, while strong repulsive forces arise between hydrophobic ends of CTAB molecules.

The XRD patterns of muscovite, Li-Mus and CTA-Mus are shown in figure 3 . The XRD patterns of muscovite observed were identical to potassium-type mica [26]. The muscovite structure was modified as there is appearance of new diffraction peaks which include (002) and (004) planes after $\mathrm{LiNO}_{3}$ and CTAB treatments, marked as hash (\#) and circle (o) symbols, respectively. The calculated $d$-values of diffraction for each sample are summarized in table 2. It is noted that the $d$ spacing of aluminosilicate layers in muscovite increased after ion exchange treatments, as the organo-clay platelets tend to repel each other. Similar findings were also observed by other researchers $[9,17,19,22]$.

The diffraction peak of the (002) plane of muscovite $2 \mathrm{M}_{1}$ arises at $8.85^{\circ}$, where the $d$-spacing of the corresponding interlayer is around $10.0 \AA$. On the other hand, the $\left(d_{002}\right)$ 
peak of Li-Mus was shifted to a lower $2 \theta$ angle, around $7.2^{\circ}$ and the gap of the interlayer had increased to $12.2 \AA$. Similarly, the diffraction peak of $\left(d_{002}\right)$ of CTA-Mus was shifted to a lower angle, $2 \theta=3.1^{\circ}$ as compared to Li-Mus and the $d$-spacing has widened to $28.4 \AA$. Hence, almost $184 \%$ increment of the $d$-spacing between aluminosilicate layers was obtained in muscovite after both $\mathrm{LiNO}_{3}$ and CTAB ion exchange treatments. Therefore, a new series of XRD line patterns was obtained for Li-Mus and CTA-Mus.

Besides, the calculated $d$-spacing for Li-Mus and CTAMus is in line with the relationship, $d_{002} \approx 2 d_{004}$ (table 2 ). Moreover, the peak height intensities of muscovite include $\left(d_{002}\right),\left(d_{004}\right),\left(d_{006}\right)$ and $\left(d_{010}\right)$ and have reduced significantly after the $\mathrm{LiNO}_{3}$ and CTAB treatments. Generally, the intensity of diffraction peaks could be affected by various factors, such as the atom species and its fractional coordination and the cell parameter [8]. Based on this finding, it can be concluded that the decrement in intensity of original peaks may be due to the existence of partial or full exfoliation between some muscovite clay layers [27].

The crystallite sizes of treated and untreated muscovite at the (002) plane are of major concern as the intercalation and exfoliation of the muscovite structure can be determined based on the crystallite size of the (002) plane. The crystallite size $(D)$ of stacked aluminosilicate layers was calculated using the Scherrer equation [28]. Then, the calculated crystallite size of stacked aluminosilicate layers was collected and summarized in table 3. The crystallite size of stacked aluminosilicate layers decreased after $\mathrm{LiNO}_{3}$ treatment and remained constant after $\mathrm{CTAB}$ treatment. Reduction in the crystallite size indicates that the lattice structure of muscovite clays becomes less rigid [24]. Therefore, a lower energy is required to modify the structure and surface properties of muscovite particles after $\mathrm{LiNO}_{3}$ treatment. The number of stacked aluminosilicate layers was reduced after $\mathrm{LiNO}_{3}$ treatment and further decreased after CTAB treatment, which indicates a significant increase in interlayer spacing of muscovite particles after ion exchange treatments.

Elemental analysis was performed on the raw muscovite, Li-Mus and CTA-Mus powders using XRF. As displayed in table 4 , decrement of $\mathrm{Na}^{+}$and $\mathrm{K}^{+}$elements sited in the aluminosilicate interlayers of muscovite was observed after the third $\mathrm{LiNO}_{3}$ treatment. This phenomenon occurs as most of the interlayer cations (potassium, $\mathrm{K}^{+}$ions) between

Table 3. $d$-values of diffraction (001) of muscovite $2 \mathrm{M}_{1}$, Li-Mus and CTA-Mus.

\begin{tabular}{lccc}
\hline Samples & $\begin{array}{c}d \text {-values of } \\
(002) \text { plane, } \\
\mathrm{nm}\end{array}$ & $\begin{array}{c}\text { Crystalline } \\
\text { size }(D), \mathrm{nm}\end{array}$ & $\begin{array}{c}\text { Number of stacked } \\
\text { aluminosilicate layers } \\
(D / d \text { values })\end{array}$ \\
\hline Muscovite $2 \mathrm{M}_{1}$ & 1 & 88.5 & 88.5 \\
Li-Mus & 1.2 & 13.5 & 11.3 \\
CTA-Mus & 2.8 & 13.5 & 4.8 \\
\hline
\end{tabular}

Table 4. Chemical composition of untreated and treated muscovite.

\begin{tabular}{lccc}
\hline & \multicolumn{3}{c}{ Mass\% } \\
\cline { 2 - 4 } Element & Muscovite & Li-Mus & CTA-Mus \\
\hline $\mathrm{Na}$ & 0.1 & 0 & 0 \\
$\mathrm{~K}$ & 7.4 & 4.5 & 4.4 \\
$\mathrm{Al}$ & 16.5 & 16.5 & 16.4 \\
$\mathrm{Si}$ & 24.9 & 25.6 & 26.2 \\
$\mathrm{Mg}$ & 0.4 & 0.3 & 0.3 \\
$\mathrm{Fe}$ & 4 & 4.9 & 5 \\
\hline
\end{tabular}

layered silicate were replaced with lithium, $\mathrm{Li}^{+}$ions during the cleavage process [8]. Thus, the aluminosilicate layers in muscovite were partially delaminated for the ease of organic ion exchange treatment.

In contrast, the ion exchange process between the alkaline earth cations, such as $\mathrm{Li}^{+}$and $\mathrm{K}^{+}$ions in the Li-Mus interlayer and $\mathrm{CTA}^{+}$cations occurred during CTAB treatment. Hence, this led to the reduction of $\mathrm{K}^{+}$ions in muscovite after CTAB treatment. Concurrently, the content of $\mathrm{Al}$ and $\mathrm{Mg}$ elements (composition of aluminosilicate layers of muscovite) was almost similar to CTA-Mus and Li-Mus. Meanwhile, the increment in the amount of $\mathrm{Fe}$ after $\mathrm{LiNO}_{3}$ treatment suggests that the contamination of Li-Mus occurred during the cleaving process. Furthermore, the amount of silica in treated muscovite also increased after $\mathrm{LiNO}_{3}$ and CTAB treatments. The increment of Si elements in treated muscovite particles was due to the effect of the grinding process which led to an increase in the amount of exposed hydroxyl bonded muscovite aluminosilicate layers. Similar observation was reported by Che Ismail and friends [24].

The effectiveness of both $\mathrm{LiNO}_{3}$ and CTAB treatments for intercalating the muscovite particles can be examined using FTIR analysis. It can be observed that there were several overlapping and new bands appeared in muscovite after both $\mathrm{LiNO}_{3}$ and CTAB treatments. The band, at about $1020 \mathrm{~cm}^{-1}$ in figure 4, is attributed to the stretching and bending vibrational motions of $\mathrm{Si}-\mathrm{O}$ bonds [8] as their vibration bands were commonly observed in the range of $1100-950 \mathrm{~cm}^{-1}$ [29]. This indicates that the backbone structure of the aluminosilicate layer for Li-Mus and CTA-Mus remains similar to muscovite $2 \mathrm{M}_{1}$ after both $\mathrm{LiNO}_{3}$ and CTAB treatments. In addition, the transmission band appeared at around $3624 \mathrm{~cm}^{-1}$ was due to the stretching motion of $\mathrm{OH}$ groups in muscovite particles. Meanwhile, the infrared transmission bands in region between $1300-500 \mathrm{~cm}^{-1}$ (figure 4) correspond to the vibrations in the aluminosilicate layers [30].

Furthermore, there were transmission bands observed at around 920, 828, 751 and $530 \mathrm{~cm}^{-1}$. The band at about $920 \mathrm{~cm}^{-1}$ was attributed to the $\mathrm{OH}$ in-plane vibration as a result of bending motion of $\mathrm{OH}$ groups arranged in the octahedral $\mathrm{Al}$ pair [8,31]. The transmission band at $828 \mathrm{~cm}^{-1}$ was attributed to the stretching motion of Al-O bonds [32]. 


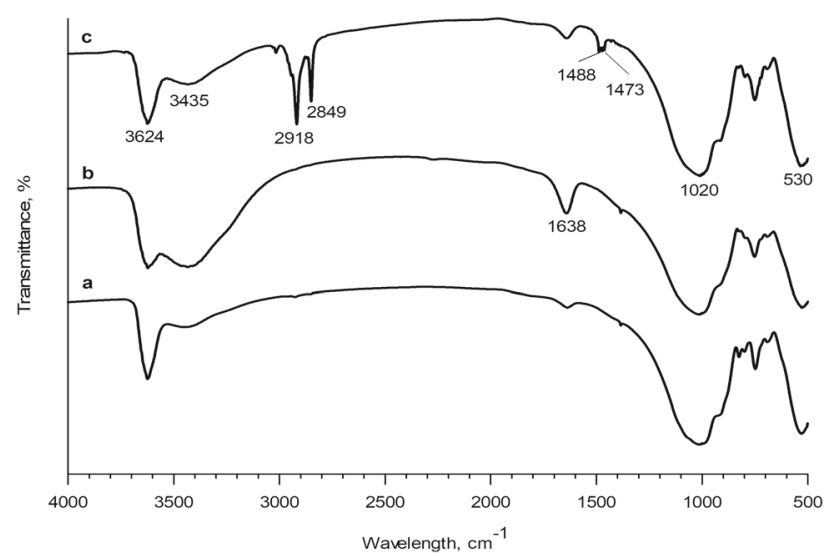

Figure 4. FTIR spectra of (a) muscovite $2 \mathrm{M}_{1}$, (b) Li-Mus and (c) CTA-Mus.

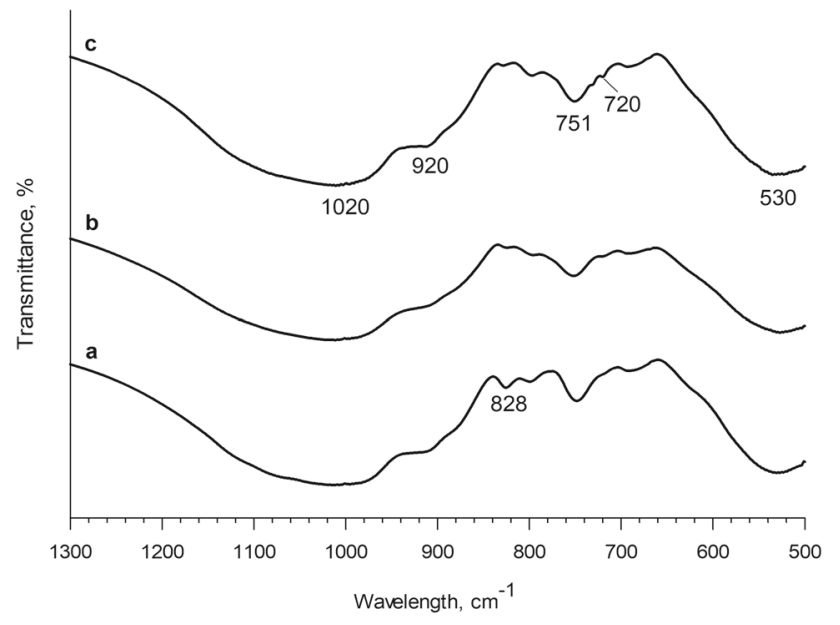

Figure 5. Selected regions of FTIR spectra of (a) muscovite $2 \mathrm{M}_{1}$, (b) Li-Mus and (c) CTA-Mus.

However, its height intensity seems to be decreased after $\mathrm{LiNO}_{3}$ treatment due to the increment of octahedral substitution content; such as $\mathrm{Fe}$ ions between the aluminosilicate layers in muscovite particles [30]. Reduction of this peak intensity is in good agreement with the results obtained in $\mathrm{XRF}$ analysis.

The infrared transmission bands detected at 751 and $530 \mathrm{~cm}^{-1}$ were corresponded to the $\mathrm{Si}-\mathrm{O}-\mathrm{Al}$ in-plane and $\mathrm{Si}-$ $\mathrm{O}-\mathrm{Al}^{\mathrm{VI}}$ vibrational motion, respectively. The intensity of the transmission band at $751 \mathrm{~cm}^{-1}$ was affected by the amount of octahedral $\mathrm{Al}$ present in the aluminosilicate layers [30]. However, the intensity of this band remained constant in the spectra of Li-Mus and CTA-Mus (figure 5b and c), indicating that the amount of octahedral $\mathrm{Al}$ in muscovite was not affected by both $\mathrm{LiNO}_{3}$ and CTAB treatments. Therefore, it can be concluded that the main structure of the aluminosilicate layers in muscovite was not damaged after $\mathrm{LiNO}_{3}$ and $\mathrm{CTAB}$ treatments. The intensity of every transmission band in the infrared spectra remains unchanged, except for the Al-O stretching vibration peak appearing at around $828 \mathrm{~cm}^{-1}$.

The intensity of new bands at around 3435 and $1638 \mathrm{~cm}^{-1}$ appeared stronger for Li-Mus after $\mathrm{LiNO}_{3}$ treatment. This indicates that a large amount of water is absorbed onto the interlayers of aluminosilicate which leads to an increment in the $d$-spacing of aluminosilicate interlayers [8]. Both new transmission bands appear in figure $4 \mathrm{~b}$ were attributed to the $\mathrm{H}_{2} \mathrm{O}$ stretching and bending vibrations, respectively. Nevertheless, the intensity of both infrared transmission bands decreased after CTAB treatment (figure 4c). As the $\mathrm{Li}^{+}$ions in aluminosilicate layers were replaced with $\mathrm{CTA}^{+}$cations, the water content in CTA-Mus nanoclays was reduced, since the amount of strong hydroscopic $\mathrm{Li}^{+}$ion content in the muscovite decreased after CTAB treatment [8].

Several new bands were present after the $\mathrm{CTA}^{+}$cations exchange process as shown in figures $4 \mathrm{c}$ and $5 \mathrm{c}$, confirming the binding of the long chain of $\mathrm{CTA}^{+}$ions on the aluminosilicate nanosheet surface. New transmission bands appeared at around 2918 and $2849 \mathrm{~cm}^{-1}$ were attributed to the stretching vibrations of asymmetric and symmetric $\mathrm{CH}_{2}$. The stretching vibration of symmetric $\mathrm{CH}_{2}$ has a lower dipole moment, thus, appearing at lower frequency [33]. Furthermore, the vibration mode of the $\mathrm{CH}_{2}$ frequency and its peak width are affected by the presence of the gauche/trans methylene chains conformer ratio $[17,18]$.

The transmission band at $1488 \mathrm{~cm}^{-1}$ of CTA-Mus was assigned to the asymmetric bending motion of the methyl head group, suggesting the formation of the bond between methyl head groups, $\left(\mathrm{CH}_{3}\right)_{3} \mathrm{~N}^{+}$and the aluminosilicate layers' surface [17]. Besides, the bands at 1473-1463 and $720 \mathrm{~cm}^{-1}$ (figures $4 \mathrm{c}$ and $5 \mathrm{c}$ ) were corresponded to the scissoring and rocking vibration mode of methylene, respectively. This phenomenon occurs due to the intermolecular interactions between the two adjacent hydrocarbon chains [9]. Based on the infrared spectrum exhibited in figure 4, it can be concluded that the ion exchange treatments were successfully performed on neat muscovite particles.

The morphological changes of muscovite after both treatments were observed using SEM (figure 6). In the beginning of the process, the aluminosilicate layers of muscovite particles were attached to each other (figure 6a). The high-electrostatic forces were present between layers and led to poor organic ion exchange treatment [34]. There were changes observed on the structure of muscovite particles after $\mathrm{LiNO}_{3}$ treatment, in which some aluminosilicate layers were partially delaminated from each other (figure 6b). It justified the XRD result obtained as the spacing of aluminosilicate interlayer was increased after $\mathrm{LiNO}_{3}$ treatment hence, allows the organic intercalation process to be performed easily. The spacing of aluminosilicate interlayers in CTA-Mus was further expanded after CTAB treatment due to the presence of the repelling effect between the organic cations present on the aluminosilicate surface layers.

Moreover, the atomic percentage of elements in untreated and treated muscovite was acquired using EDX analysis 


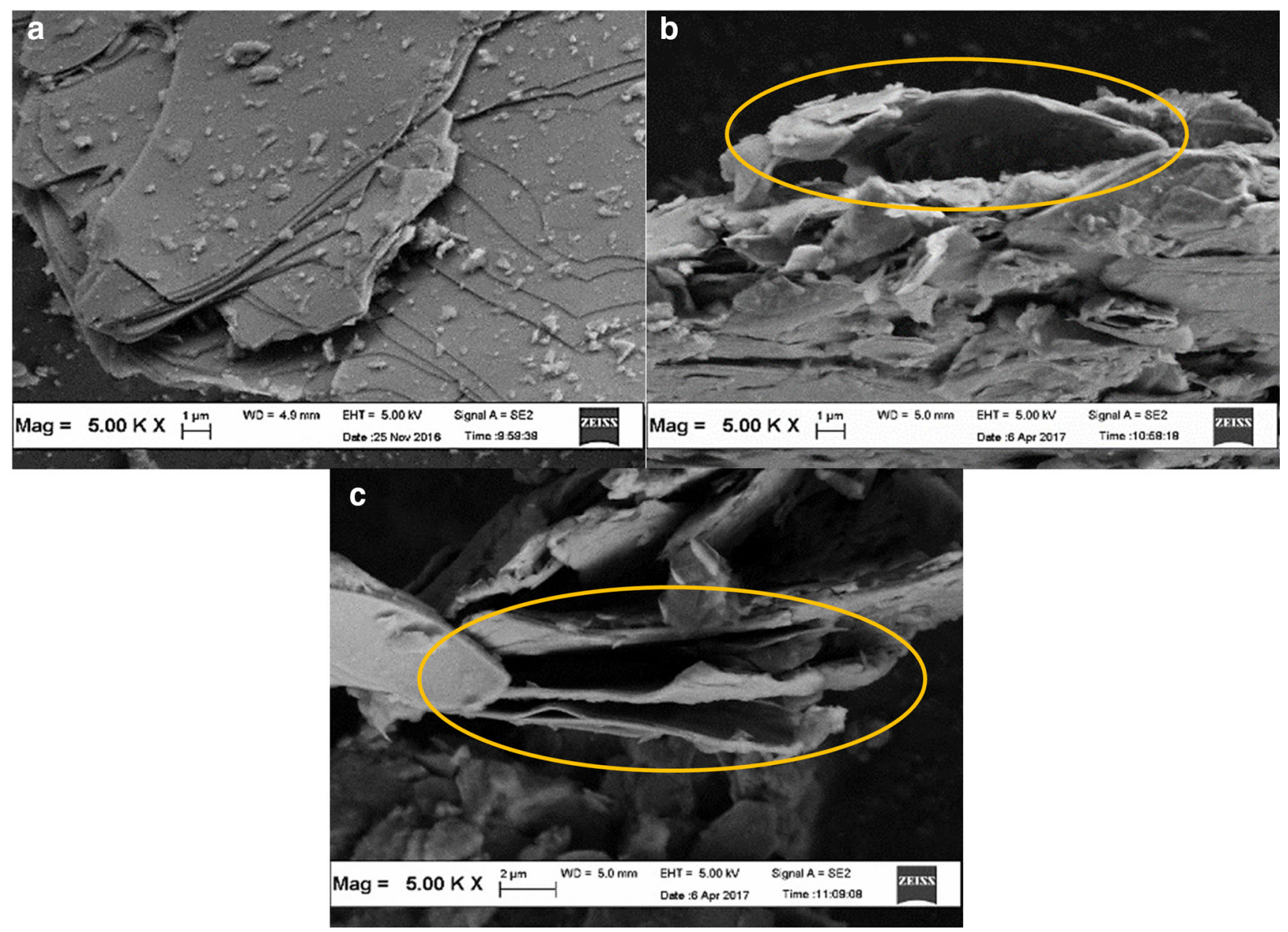

Figure 6. SEM images of (a) muscovite $2 \mathrm{M}_{1}$, (b) Li-Mus and (c) CTA-Mus at $5 \mathrm{k} \times$ magnification.

Table 5. EDX analysis of untreated and treated muscovite.

\begin{tabular}{lrrrr}
\hline & \multicolumn{4}{c}{ Atomic\% } \\
\cline { 2 - 4 } & & \multicolumn{2}{c}{ Li-Mus } \\
\cline { 2 - 4 } Element & Muscovite & First treatment & Third treatment & CTA-Mus \\
\hline Oxide, O & 50.6 & 55.1 & 51.7 & 43.8 \\
Potassium, K & 6.7 & 4.2 & 2.8 & 2.7 \\
Aluminium, Al & 17.4 & 15.2 & 18.5 & 21.2 \\
Silicon, Si & 22.4 & 21.7 & 23.2 & 28.6 \\
Magnesium, Mg & 0.8 & 1.4 & 1.6 & 1.6 \\
Iron, Fe & 2.2 & 2.4 & 2.2 & 2.2 \\
\hline
\end{tabular}

(table 5). The EDX analysis suggests that oxygen, $\mathrm{O}_{2}$ contributed major elements for muscovite, Li-Mus and CTAMus. The amount of potassium, $\mathrm{K}$ element decreased significantly after $\mathrm{LiNO}_{3}$ treatment and further decreased after CTAB treatment. On the other hand, the amounts of Si and $\mathrm{Al}$ elements (main composition of aluminosilicate layers) present in CTA-Mus and Li-Mus nanoclays were almost similar.
Microstructural changes of muscovite after $\mathrm{LiNO}_{3}$ and CTAB treatments were observed using HRTEM. Figure 7 illustrates the ultrathin section of muscovite, Li-Mus and CTA-Mus samples. The (002) plane of muscovite remained in a parallel and compact interlayer spacing configuration arrangement after $\mathrm{LiNO}_{3}$ and CTAB treatments. The aluminosilicate interlayers' spacing of raw muscovite (figure 7a) is $10 \AA$. This result is in agreement with the $d$-spacing of 

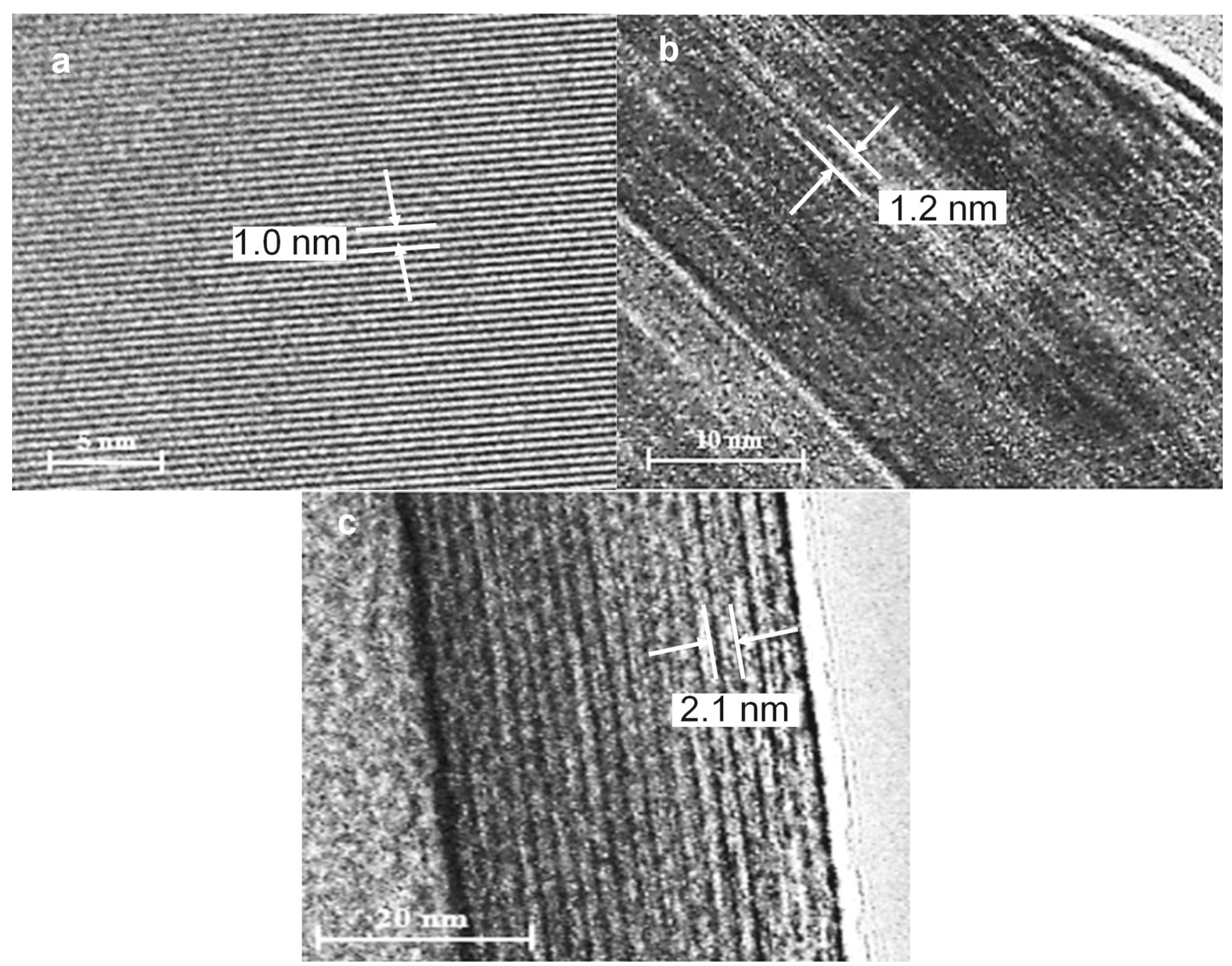

Figure 7. HRTEM images of (a) muscovite $2 \mathrm{M}_{1}$, (b) Li-Mus and (c) CTA-Mus samples in an ultrathin section.

the (002) plane of muscovite in XRD analysis (table 2). Furthermore, the galleries of muscovite were enlarged after $\mathrm{LiNO}_{3}$ treatment. This phenomenon occurs due to the alkali ion exchange process that took place on the aluminosilicate layer surface, where some $\mathrm{K}^{+}$and $\mathrm{Na}^{+}$ions were replaced with $\mathrm{Li}^{+}$ions during the cleaving process. Hence, this led to the expansion of $d_{002}$ spacing in Li-Mus from $10 \AA$ to about $12 \AA$. The interlayer spacing of $\left(d_{002}\right)$ obtained via HRTEM analysis for Li-Mus is almost similar to the XRD result, which is $12.2 \AA$.

In addition, the $d$-spacing of aluminosilicate layers in muscovite was further increased via the organic ion exchange treatment. The HRTEM image of CTA-Mus (figure 7c) shows a spacing of $21 \AA$ for the (002) plane. The expansion of CTAMus aluminosilicate interlayer spacing was attributed to the repelling effect of the organo-cation that present on the silicate layer surface [17]. A slight difference in the (002) plane spacing of CTA-Mus was observed via the HRTEM image as compared to the $d$-spacing obtained (28.4 $\AA$ ) in XRD analysis. According to Lee and Kim [35], the occurrence of this phenomenon may be due to the collapse of aluminosilicate layers when collided with the electrons during HRTEM observation.

\subsection{Effect of reaction time during hydrothermal process}

Diffraction peaks and $d$-spacing values of CTA-Mus samples treated at different hydrothermal reaction times are shown in figure 8 and table 6 , respectively. The structure of all CTAMus samples was modified by the organic treatment as their $d$-values of the (002) plane diffraction peak were augmented from $12.2 \AA$ ( $d$-values of Li-Mus) to $28.4 \AA$. By varying the reaction times, the type of arrangement of organic molecules within the interlamellar spacing of clay platelets could be deduced from the increment of basal spacing. According to the literature, the organic molecules are arranged in the form of monolayer, bilayer, pseudo-trimolecular layer or paraffin complex between the clay unit layers $[36,37]$.

Initially, the aluminosilicate interlayer spacing of the (002) plane in muscovite was calculated to be $\sim 10.0 \AA$, whereas 


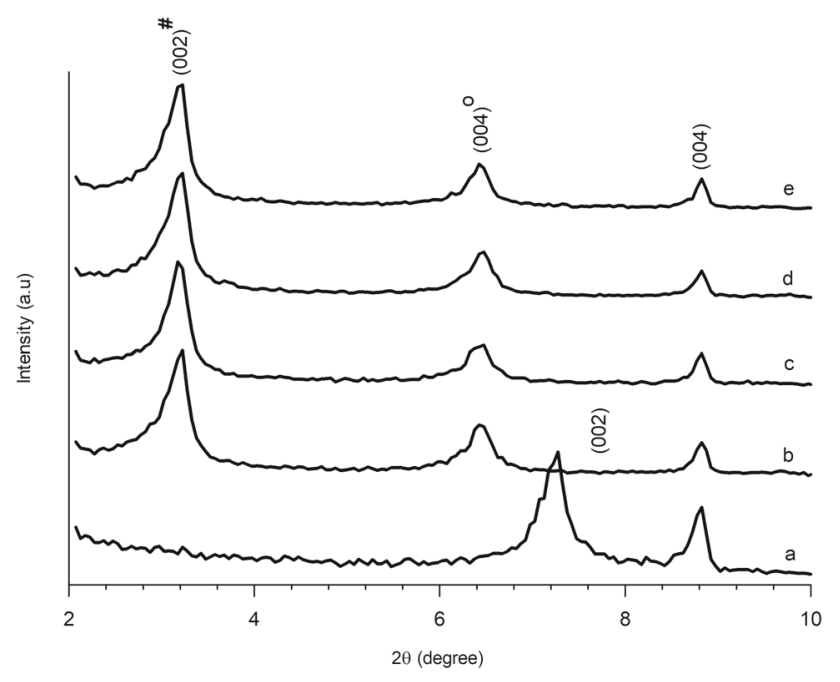

Figure 8. XRD patterns of (a) Li-Mus, (b) CTA-Mus 12, (c) CTAMus 16, (d) CTA-Mus 20 and (e) CTA-Mus 24.

Table 6. $d$-values of diffraction (001) obtained from the XRD pattern of samples at different hydrothermal reaction times.

\begin{tabular}{|c|c|c|}
\hline \multirow[b]{2}{*}{ Samples } & \multicolumn{2}{|c|}{$d$-values of diffraction $(001), \AA$} \\
\hline & $d_{002} \#$ & $d_{004^{\circ}}$ \\
\hline Li-Mus & 12.2 & 6.1 \\
\hline CTA-Mus 12 & 28.4 & 13.8 \\
\hline CTA-Mus 16 & 28.3 & 13.8 \\
\hline CTA-Mus 20 & 28.3 & 13.9 \\
\hline CTA-Mus 24 & 28.4 & 13.8 \\
\hline
\end{tabular}

the diameter of $\mathrm{K}^{+}$ions is generally $\sim 2.7 \AA$ [38]. Thus, the thickness of aluminosilicate sheets in the muscovite is around $7.3 \AA$. In addition, the fully stretched $\mathrm{CTA}^{+}$chain length is about $23.6 \AA[39,40]$. Thus, the spacing of aluminosilicate interlayers left in the half unit cell is $\sim 21.1 \AA(28.4-7.3 \AA)$ after considering the $d$-spacing of CTA-Mus samples (table 6 ) and the calculated thickness of aluminosilicate sheets.

Hence, based on the $d$-spacing values obtained for all samples at different hydrothermal reaction times, the CTA ${ }^{+}$ cations were bonded with the respective aluminosilicate layer surface in the perpendicular or tilted arrangement (paraffintype bilayer configuration) as spacing of aluminosilicate layers in CTA-Mus samples was almost equivalent to the length of the fully stretched $\mathrm{CTA}^{+}$-chain (figure 1). Paraffin arrangement of the $\mathrm{CTA}^{+}$-chain allows homogeneous charge distribution of the organic cation, $\mathrm{CTA}^{+}$throughout aluminosilicate layers which results in higher charge density [9]. Moreover, the (002) plane diffraction peaks of CTA-Mus samples were almost similar in terms of the position and their $d$-value as the hydrothermal reaction time is prolonged to more than $12 \mathrm{~h}$. An increase in the basal spacing and paraffin arrangement of $\mathrm{CTA}^{+}$of treated muscovite is important for

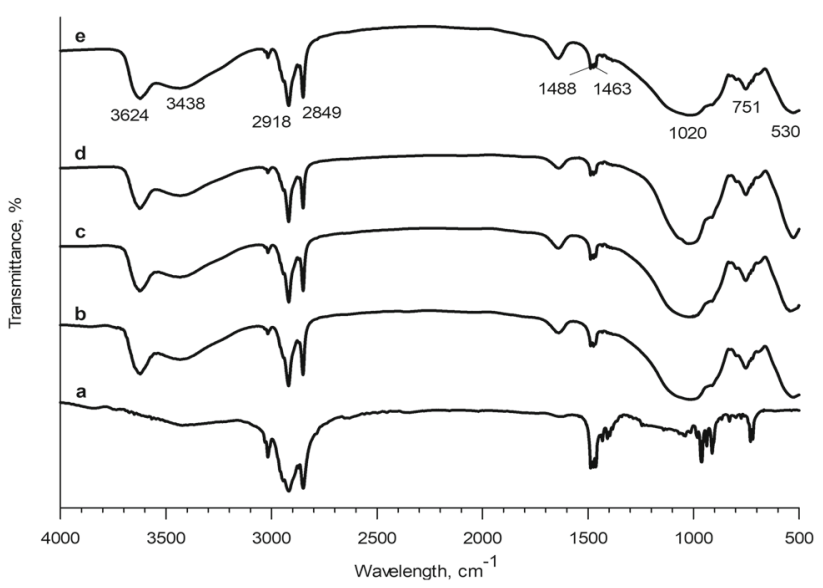

Figure 9. FTIR spectra of (a) CTAB and CTA-Mus samples ((b) CTA-M 12, (c) CTA-M 16, (d) CTA-M 20 and (e) CTA-M 24) prepared at different hydrothermal reaction duration.

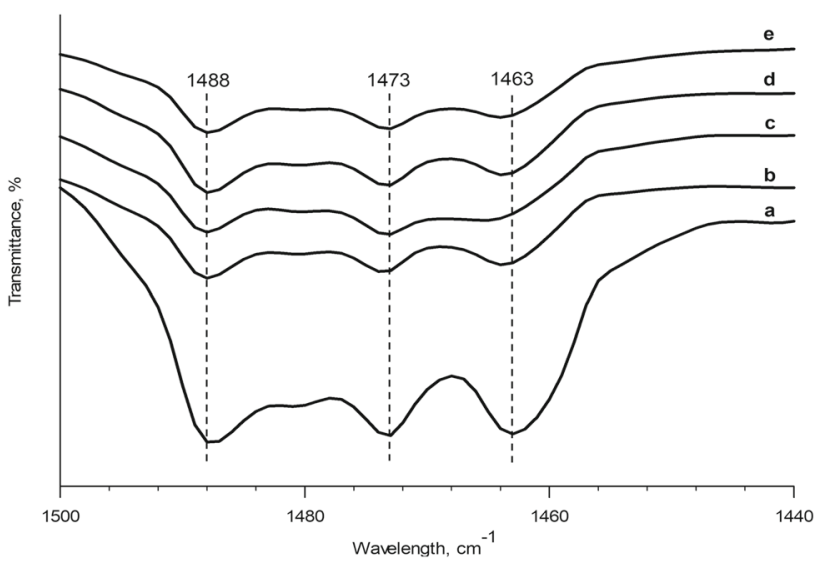

Figure 10. FTIR spectra of (a) CTAB and CTA-Mus samples ((b) CTA-M 12, (c) CTA-M 16, (d) CTA-M 20 and (e) CTA-M 24) prepared at different hydrothermal reaction duration in selected region at $1500-1440 \mathrm{~cm}^{-1}$.

the interaction between the polymer matrix with muscovite as a filler during the preparation of polymer composites. The head of CTAB is attached to the muscovite surface, while the tail will interact with the polymer matrix hence, promote strong adhesion between the filler/matrix interface. This phenomenon will aid the compatibility between the filler and matrix and enhance the dispersion of filler hence, further improve the final properties of the polymer composite.

The FTIR spectra of CTA-Mus samples prepared at 12, 16, 20 and $24 \mathrm{~h}$ are shown in figures 9 and 10 . It is observed that the intensity of the transmission bands in the spectra of all CTA-Mus samples was almost unchanged. Furthermore, the asymmetric bending vibration of the $\left(\mathrm{CH}_{3}\right)_{3} \mathrm{~N}^{+}$group at around $1488 \mathrm{~cm}^{-1}$ in all samples is almost similar to the crystalline CTAB (figure 10). This indicates that the head groups of $\mathrm{CTA}^{+}$ions in all samples are homogeneously distributed and form bonding with the aluminosilicate layers' surface 


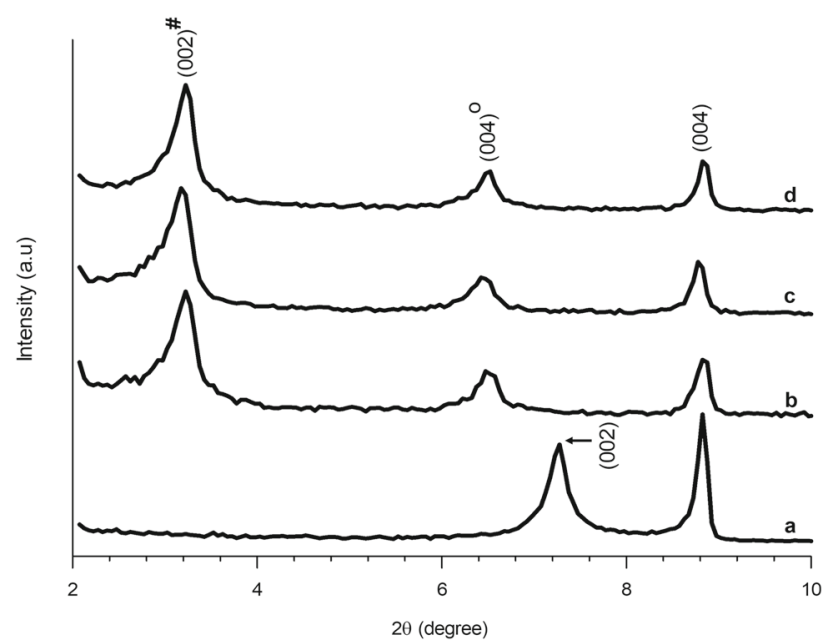

Figure 11. XRD patterns of (a) Li-Mus, (b) CTA-Mus $0.5 \mathrm{C}$, (c) CTA-Mus 1.0 C and (d) CTA-Mus 1.5 C.

Table 7. $d$-values of diffraction (001) obtained from XRD patterns of samples in different CTAB to Li-Mus mass ratios.

\begin{tabular}{lcc}
\hline \multirow{2}{*}{ Samples } & \multicolumn{2}{c}{$d$-values of diffraction (001), $\AA$} \\
\cline { 2 - 3 } & $d_{002^{\#}}$ & $d_{004^{\circ}}$ \\
\hline Li-Mus & 12.2 & 6.1 \\
CTA-Mus 0.5 C & 28.4 & 13.8 \\
CTA-Mus 1.0 C & 28.6 & 13.8 \\
CTA-Mus 1.5 C & 28 & 13.7 \\
\hline
\end{tabular}

[9]. Therefore, the intercalation process of $\mathrm{CTA}^{+}$cations into muscovite particles is not significantly enhanced by further increase in the duration of the hydrothermal reaction up to $16 \mathrm{~h}$ and more.

\subsection{Effect of CTAB concentration}

XRD diffraction peaks of CTA-Mus samples with different $\mathrm{CTAB}$ to Li-Mus mass ratios prepared in the hydrothermal reaction at $180^{\circ} \mathrm{C}$ for $12 \mathrm{~h}$ are shown in figure 11 and the value of $d_{002}$ is summarized in table 7 . The value of $d_{002}$ in CTA-Mus increased gradually with the CTAB to Li-Mus mass ratio. However, the $d$-spacing of interlayers declines beyond 1.0 mass ratio of CTAB to Li-Mus. The space available in the gallery of the interlayer seems to be fully occupied by $\mathrm{CTA}^{+}$ ions at 1.0 as it is the threshold concentration limit.

Figure 12 illustrates the FTIR spectra of CTA-Mus samples prepared at $0.5,1$ and 1.5 mass ratios of CTAB to Li-Mus. The intensity of both asymmetric and symmetric $\mathrm{CH}_{2}$ stretching bands was gradually increased with the CTAB to Li-Mus mass ratio. However, the intensity of these bands remained almost constant once the mass ratio of CTAB to Li-Mus is beyond the threshold concentration limit (1 C). The intensity of both $\mathrm{CH}_{2}$ bands was similar to both CTA-M $1 \mathrm{C}$ and

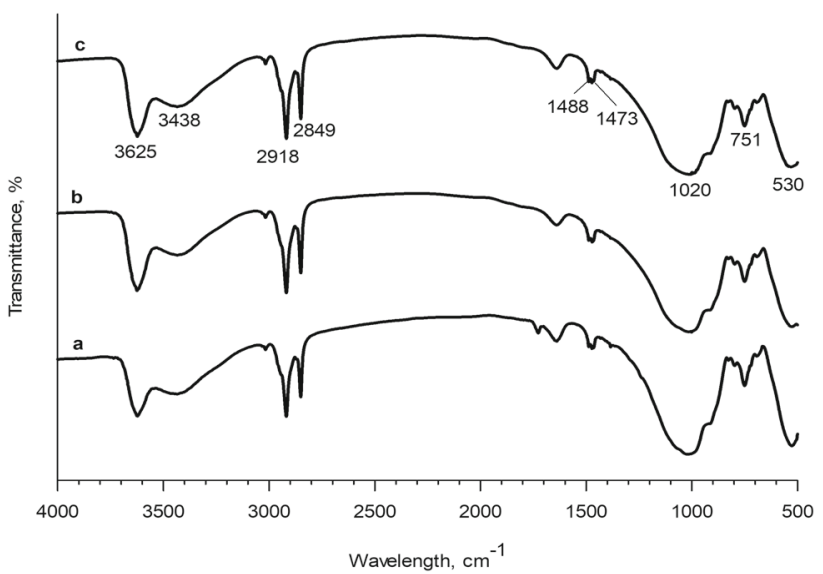

Figure 12. FTIR spectra of CTA-Mus samples prepared at different ratios: (a) CTA-M 0.5 C, (b) CTA-M 1.0 C and (c) CTA-M $1.5 \mathrm{C}$.

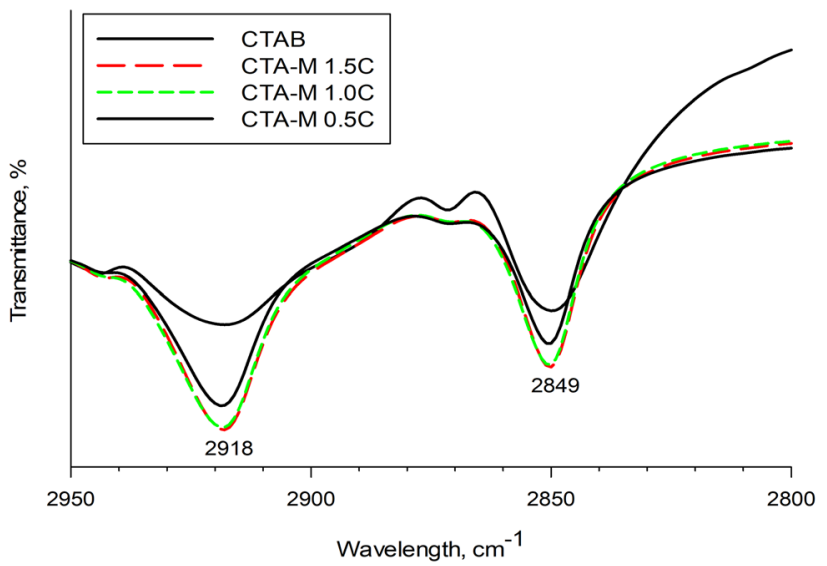

Figure 13. FTIR spectra of CTA-Mus samples prepared at different ratios in a selected region between $2950-2800 \mathrm{~cm}^{-1}$.

CTA-M 1.5 C, even the mass ratio of CTAB to Li-Mus is increased (figure 13). Hence, it can be concluded that threshold of the CTAB to Li-Mus mass ratio is limited to the amount of not more than 1 ratio.

Therefore, the information obtained on the changes of basal spacing and surfactant arrangement in the treated organoclay as a function of reaction time and $\mathrm{CTAB}$ concentration during the hydrothermal reaction may allow the tailor of polymer intercalation to a specific purpose.

\section{Conclusion}

Alkylammonium cations were successfully intercalated within the aluminosilicate layers of muscovite using a two-step intercalation method. The chemical properties as well as the morphological and structural changes of the intercalated muscovite clay were explored via several analytical techniques. XRD analysis showed that the $d_{002}$ plane 
spacing of muscovite clays had enlarged from 10 to $12.2 \AA$ after $\mathrm{LiNO}_{3}$ treatment. In addition, decrement of $\mathrm{K}^{+}$and $\mathrm{Na}^{+}$ions observed via EDX analysis after $\mathrm{LiNO}_{3}$ treatment, suggesting the replacement with $\mathrm{Li}^{+}$ions. Furthermore, $\mathrm{CTA}^{+}$-intercalated muscovite was obtained after ion exchange treatment between inorganic and organic cations via the hydrothermal process. After CTAB treatment, $d$-values of the (002) plane had increased significantly to $28.4 \AA$. FTIR analysis of CTA-Mus indicated that the head groups of $\mathrm{CTA}^{+}$were uniformly distributed on the surface of aluminosilicate layers due to the electrostatic bond. The effect of the hydrothermal reaction time and the CTAB to Li-Mus mass ratio was investigated during CTA-Mus preparation at $180^{\circ} \mathrm{C}$ and several findings were observed. First, the arrangement and intercalation of $\mathrm{CTA}^{+}$chains were not affected by the duration of the hydrothermal reaction, since the $d$-spacing of the (002) plane for all the samples prepared at different reaction times are almost similar, $d \sim 28.4 \AA$. Besides, the $\mathrm{CTA}^{+}$chain arrangement in the CTA-Mus samples appeared in a fully stretched paraffin-like structure. Hence, the optimum reaction time for CTAB treatment under hydrothermal conditions at $180^{\circ} \mathrm{C}$ was obtained at $12 \mathrm{~h}$. Secondly, there were optimum limit observed during the preparation of CTAMus at different CTAB to Li-Mus ratios. The $d$-values of the (002) plane of CTA-Mus is increased with the mass ratio up to 1 and decreased with a further increase in the mass ratio. Thus, the optimum mass ratio in obtaining almost fully intercalated CTA-Mus sample is taken as 1 mass ratio with $28.6 \AA$ basal spacing. Apart from this, FTIR analysis suggested that the structure of aluminosilicate layers was not affected and damaged after both $\mathrm{LiNO}_{3}$ and CTAB treatments. Therefore, the surface treatments of the muscovite layers in this study allows for further exploration of their potential use as filler materials in various applications.

\section{Acknowledgements}

This study was financially supported by short term grant of Universiti Sains Malaysia (grant no. 304/PBAHAN/60313035).

\section{References}

[1] Bekri-Abbes I and Srasra E 2006 Bull. Mater. Sci. 29251

[2] Murray H H 1991 Appl. Clay Sci. 5379

[3] Sharma S, Kumar P M and Moholkar V S 2017 Ultrason. Sonochem. 36212

[4] Jahanmardi R, Kangarlou B and Dibazar A 2013 J. Nanostruct. Chem. 382

[5] Strankowska J, Piszczyk Ł, Strankowski M, Danowska M, Szutkowski K, Jurga S et al. 2013 Eur. Phys. J. Spec. Top. 2222179

[6] Xi X, Zhen W, Bian S and Wang W 2015 Polymer (Korea) 39 601
[7] Mousa M H, Dong Y and Davies I J 2016 Int. J. Polym. Mater. Polym. Biomater. 65225

[8] Yu X, Zhao L, Gao X, Zhang X and Wu N 2006 J. Solid State Chem. 1791569

[9] Yu X, Zhao L, Gao X, Zhang X and Wu N 2006 J. Solid State Chem. 1791525

[10] Omar M F, Akil H M, Ahmad Z A, Rasyid M F A and Noriman N Z 2016 J. Thermoplast. Compos. Mater. 29867

[11] Rashid E S A, Rasyid M F A, Akil H M, Ariffin K and Kooi C C 2011 Appl. Clay Sci. 52295

[12] Kudus M H A, Akil H M and Rasyid M F A 2012 Mater. Lett. 7992

[13] Aitta E, Leskelä M, Lajunen L H J, Jyrkäs K and Seppälä E 1986 J. Chem. Technol. Biotechnol. 36169

[14] Caseri W R, Shelden R A and Suter U W 1992 Colloid Polym. Sci. 270392

[15] Leiro J A, Torhola M and Laajalehto K 2017 J. Phys. Chem. Solids 10040

[16] Almeida L A, de Marques M F V and Dahmouche K 2018 J. Appl. Polym. Sci. 13545587

[17] Omar M F, Akil H M, Rasyid M F A and Sharif J M 2015 J. Compos. Mater. 491195

[18] Yu X 2007 Micropor. Mesopor. Mat. 9870

[19] Bracke G, Satir M and Krauß P 1995 Clays Clay Miner. 43732

[20] Kodama T, Hasegawa K, Shimizu K and Komarneni S 2003 Sep. Sci. Technol. 38679

[21] Shimizu K, Hasegawa K, Nakamuro Y, Kodama T and Komarneni S 2004 J. Mater. Chem. 141031

[22] Zhao L Y, Wang X K, Wu N Z and Xie Y C 2005 Colloid Polym. Sci. 283699

[23] Metz S, Anderson R L, Geatches D L, Suter J L, Lines R and Greenwell H C 2015 J. Phys. Chem. C 11912625

[24] Che Ismail N H, Ahmad Bakhtiar N S A and Md Akil H 2017 Mater. Chem. Phys. 196324

[25] Bae H J, Goh Y, Yim H, Yoo S Y, Choi J W and Kwon D K 2019 Mater. Chem. Phys. 221168

[26] Tominaga Y, Fukushima K, Takezawa Y, Shimamoto D, Imai Y and Hotta Y 2017 Adv. Powder Technol. 281911

[27] Pozsgay A 2004 Eur. Polym. J. 4027

[28] Paul R, Datta S C, Manjaiah K M and Bhattacharyya R 2017 Appl. Clay Sci. 14419

[29] Ramadan A R, Esawi A M K and Gawad A A 2010 Appl. Clay Sci. 47196

[30] Sayin M and Von Reichenbach H G 1978 Clay Miner. 13241

[31] Stubičan V and Roy R 1961 Am. Mineral. 4632

[32] Farmer V C and Russell J D 1964 Spectrochim. Acta 201149

[33] Olad A 2011 in Reddy B (ed) Advances in diverse industrial applications of nanocomposites (Croatia: InTech) p 122

[34] Garcia A D and Catterton A J 2003 Microgram J. 144

[35] Lee S Y and Kim S J 2002 Clays Clay Miner. 50435

[36] Saeid G, Mark T B and Andrew B 1997 J. Colloid Interface Sci. 196191

[37] Xi Y, Frost R L and He H 2007 J. Colloid Interface Sci. 305 150

[38] Karp G 2013 in Witt K, Stauber L, Morris L (eds) Cell and molecular biology: concepts and experiments, 7th edn (Hoboken, NJ: John Wiley \& Sons Ltd) p 120

[39] Wang L, Chen Z, Wang X, Yan S, Wang J and Fan Y 2011 Appl. Clay Sci. $\mathbf{5 1} 151$

[40] Liang Y, Ding H, Wang Y, Liang N and Wang G 2013 Appl. Clay Sci. 74109 